\title{
Research on the Status Quo and Countermeasures of Technological Innovation Development of Private Enterprises in Zhuhai
}

\author{
Xue Cheng ${ }^{1}$ Wei Chen ${ }^{2, *}$ \\ ${ }^{1}$ Zhuhai College Jilin University, Zhuhai, Guangdong 519041, China \\ ${ }^{2}$ Financial Business Center of Benxi County, Liaoning Province, Benxi, Liaoning 117000, China \\ *Corresponding author. Email: wxd6829660@163.com
}

\begin{abstract}
With the continuous progress of the times, innovation and development have almost become the driving force for all enterprises. In July 2020, General Secretary Xi emphasized at the symposium on entrepreneurs that private enterprises must grasp the key technology core, and the responsibility lies on their shoulders. This paper studies the technological innovation capabilities of private enterprises in Zhuhai under the innovation-driven strategy, summarizes the development of private technology investment and independent innovation capabilities, the number and proportion of private high-tech enterprises, the scale and layout of private enterprises, looks for problems in the process of technological innovation and development of private enterprises, and explores countermeasures to improve the technological innovation capability of private enterprises in Zhuhai, which is of great significance to the development, transformation and upgrading of private enterprises and the development of private economy.
\end{abstract}

Keywords: Zhuhai, Private enterprises, Technological innovation.

\section{INTRODUCTION}

Innovation is the first driving force for development. Private enterprises will still have certain difficulties in the process of technological innovation. Zhuhai Municipal Government and private enterprises can cooperate with each other to promote innovation and development more effectively. Based on relevant data, this article analyzes the development status of Zhuhai's private enterprises' technological innovation from multiple angles, discovers the existing problems and proposes countermeasures.

*Project: The Innovation Ability Cultivation Project Fund Project of Zhuhai College of Jilin University: Research on the Status Quo and Countermeasures of Technological Innovation Development of Private Enterprises in Zhuhai, Project No.: 2020XJCQ036.
2. THE STATUS QUO OF TECHNOLOGICAL INNOVATION OF PRIVATE ENTERPRISES IN ZHUHAI

\subsection{Condition of Private Technology Investment and Independent Innovation Capabilities Development}

R\&D indicators can intuitively reflect the level of enterprise innovation capabilities and have been improved based on the availability of data. According to data from China Business Intelligence Network, in 2019, Guangdong Province invested a total of 309.849 billion yuan in R\&D expenditures, an increase of 39.379 billion yuan over the previous year, an increase of $14.6 \%$, and the investment intensity of R\&D expenditure in Guangdong Province (ratio to the GDP of all regions of the province) is $2.88 \%$. Zhuhai ranks sixth in Guangdong Province with 10.935 .6 billion yuan in scientific research funding. There are only 3 cities 
in Guangdong where the intensity of R\&D funding investment exceeds the average level of the province, which the three cities are Shenzhen (4.93\%), Zhuhai (3.15\%), and Dongguan (3.06\%) respectively. At present, Zhuhai is still strengthening the development of technological innovation in private enterprises in terms of enterprise technological transformation and promotion of the development of this generation of information technology industry, and gradually investing in supporting projects for the promotion of high-quality development of the real economy in Zhuhai in a systematic way.

\subsection{Number and Proportion of Private High-tech Enterprises}

As of February 8, 2021, according to the "Zhuhai High-tech Enterprise List" update, there are currently 2,203 high-tech enterprises in Zhuhai City (Data source: Zhuhai Citizens' Livelihood Data Open Platform http://data.zhuhai.gov.cn/\# /data/detail/1062). From 2014 to 2019, the added value of the private economy in Zhuhai increased by more than $8 \%$ annually. In 2019, the added value of the private economy reached 140.346 billion yuan, and the added value of the private economy accounted for $40.8 \%$ of GDP. (Data source: Zhuhai Special Zone News, http://zhuhaidaily.hizh.cn/h5/html5/2020-

08/26/content_1289_3190091.htm) Zhuhai private enterprises are one of the most energetic and vigorous in the national economy of Zhuhai's highlights, becoming the backbone that supports and promotes Zhuhai's economic growth. In 2019, in the face of the complex and changeable international and Chinese situation, all indicators of Zhuhai's private economy have maintained a significant growth trend. The private tertiary industry structure of $4.0: 37.2: 58.7$ is gradually transforming into a technology-intensive industry. The tertiary industry has shown benign interactive adjustments, and the industrial structure has been continuously optimized. In 2020, in the face of the impact of the epidemic, Zhuhai promptly introduced the "ten measures for resuming work and production" and the "1+7" policy for stable growth. Various measures have been directed to physical enterprises, and the city's industrial production has gradually recovered steadily. The annual added value of strategic emerging industries, advanced manufacturing and high-tech manufacturing were 49.232 billion yuan, 69.899 billion yuan and 37.047 billion yuan, the proportions that accounted for the value added of the industrial enterprises above designated size were $41.0 \%, 58.2 \%$, and $30.9 \%$, respectively, and the growth rates were $3.0 \%, 3.0 \%$, and $6.3 \%$, respectively. (Data source: Hong Kong and Macao Affairs Office of the People's Government of Guangdong Province, http://hmo.gd.gov.cn/dwqjz/content/post_3222755. html)

\subsection{Industrial Scale and Layout of Private Enterprises}

In 2020, the Hurun Research Institute released the "2020 Shimao Strait - Hurun Top 500 Private Enterprises in China", which lists the top 500 private companies in China. Zhuhai has five companies on the list, namely Gree Electric, Jianfan Biotechnology Group, Livzon Group, By-Health and Ninestar. The "2020 Zhuhai Top 100 Private Enterprises" list released by the Zhuhai Enterprise and Entrepreneurs Association shows that Gree Electric, Sinopec Sales Co., Ltd. Guangdong Zhuhai Petroleum Branch, and Zhuhai Xiaomi Technology Co., Ltd. are the top three private enterprises in Zhuhai. Ninestar Co., Ltd. is the fourth largest private enterprise in Zhuhai City. Among the top ten private enterprises in Zhuhai, 4 are manufacturing companies and 6 are service companies. This also reflects Zhuhai's highly developed urban economic and social development level. According to geographical distribution, the top ten private companies are 2 companies are located in Xiangzhou District, 2 companies are located in Wanshan District, 2 companies are located in High-tech Zone, 2 companies are located in Hengqin New District, and 2 companies are located in Jinwan District.

\section{THE PROBLEMS EXISTING IN THE TECHNOLOGICAL INNOVATION OF PRIVATE ENTERPRISES IN ZHUHAI}

\subsection{Investment in Scientific and Technological Research and Development and Capacity for Independent Innovation Are Insufficient}

Although Guangdong Province invested 309.849 billion yuan in R\&D funds in 2019 , according to the breakdown of activities, R\&D funds were mainly used for industrial enterprises 237.463 billion yuan, and government scientific 
research institutions accounted for only 112.16, a decrease of $37.2 \%$ from the previous year. As a whole, the Guangdong Provincial Government has invested less in scientific research institutions. Zhuhai has a great advantage in the total and proportion of R\&D investment in PRD(Pearl River Delta). Compared with Chaoyang, Heyuan, and Meizhou, which have less than 1 billion expenditures, Zhuhai is already a region that places more emphasis on scientific and technological research. However, compared with the top five economic investment regions, Shenzhen (132.828 billion yuan), Guangzhou (67.774 billion yuan), Dongguan (28.996 billion yuan), Foshan (28.741 billion yuan), and Huizhou (10.935 billion yuan), there is still a need to increase investment, and rectify and optimize. (Data source: China Business Intelligence

Network, https://www.askci.com/news/data/hongguan/20201 121/1021071289626.shtml) Insufficient R\&D funding has made Zhuhai's high-tech industry weaker in research and development. Most of the core technologies and key supporting products rely on foreign supplies, the proportion of products with independent intellectual property rights is low, and most high-tech enterprises are still in the processing and manufacturing links at the bottom of the international manufacturing industry chain. As of January 2021, there are 3406 SMEs in the list of high-tech small and medium-sized enterprises in Zhuhai High-tech Zone. Most of Zhuhai's high-tech industries are small in scale and slow in growth. As a result, the ability to gather innovation resources is insufficient, and the pulling effect on demand is not strong, and the driving force for industrial transformation and upgrading and economic growth still needs to be further improved.

\subsection{There Is a Shortage of High-tech Talents, and the Contradiction Between the Supply and Demand of Talents Is Obviously Intensified}

With the continuous increase in the transformation and upgrading of various industries, the demand for talents in Zhuhai has gradually begun to change. The demand for talents in traditional industries has become saturated, the introduction of high-tech talents has become more difficult, and the talent market reserves are not high enough to match the talents required by the regional industry development goals. Colleagues engaged in scientific research in Zhuhai are still unable to meet market demands. It is becoming more and more urgent to introduce, develop and cultivate high- level innovative talents who can lead the development of the industry and participate in international competition. Although Zhuhai has a sound talent introduction strategy with corresponding subsidies in the municipal and district governments, relevant professional and technical talents still lack policy interpretation, and the policy publicity for talent introduction is insufficient.

\subsection{The Industrial Chain Is Imperfect, and the Driving Effect of Industrial Upgrading Is Weak}

Among the top ten private enterprises in Zhuhai, Zhuhai, 4 are manufacturing companies and 6 are service companies. From the perspective of the industrial chain, similar or related enterprises in various industrial parks still lack close collaboration and symbiosis with each other, the industrial chain is loose, and the synergy between upstream and downstream enterprises, large and medium-sized enterprises, leading enterprises and supporting enterprises in the region has not been fully utilized, and the industrial collaboration system still needs to be improved. From the perspective of regional distribution, there are excellent high-tech enterprises in the five districts of Zhuhai. As the manufacturing industry accounts for a relatively large proportion, the high-end production service industries such as independent research and development design and marketing, branding are relatively low. The development of the science and technology service system is relatively lagging, and the penetration and driving effect of the high-tech industry on the upgrading of the manufacturing structure is relatively weak, and it is difficult to achieve effective interaction and coordinated development between the high-tech industry and the local manufacturing industry. Zhuhai and Macau are close to the each other. The University of Macau has introduced resources for setting up branch campuses and has excellent university resources. It seems to be rich in production, learning, and research resources, but it has not yet reached a perfect fit, and there is still a lot of room for development. 


\section{COUNTERMEASURES TO IMPROVE THE TECHNICAL INNOVATION ABILITY OF PRIVATE ENTERPRISES IN ZHUHAI}

\subsection{Increasing the Government's Special Investment in Scientific Research Finance}

Compared with other provinces and cities in Guangdong Province, Zhuhai is already in the forefront of special financial investment in scientific research. However, in the face of the slow upgrading of small and medium-sized private enterprises, the municipal government still has to provide support to meet enterprise technological innovation as much as possible. Relevant financial departments can provide tax incentives for small and medium-sized enterprises, and reserve special funds every year to reward innovative accounts. At present, Zhuhai has achieved initial results in this regard. It is also necessary to upgrade and optimize, increase publicity, use the government's special investment in scientific research to the extreme, further increase the total amount and support of the special fund for technological innovation of small and medium-sized enterprises, and favorably support the development of small and mediumsized high-tech enterprises. Relevant government departments should learn from France and other foreign countries' excellent deployment plans, pay attention to investment in innovative research, introduce advanced technologies, and continue to digest and re-develop. The government can also provide credit guarantees for small and mediumsized enterprises. A complete credit guarantee system can effectively compensate for the problems of technology-based private enterprises that are difficult to obtain loans due to high innovation risks and small asset values, reducing the loan risks of financial institutions and lowering financing costs.

\subsection{Improving the Talent Introduction System of Government Enterprises}

First of all, according to the dual talent introduction subsidies + capacity expansion of the enterprise and the government, excellent talents need to be attracted to join the Zhuhai talent pool. The top management of the enterprise should respond to the excellent technical talents, and emphasize the foresight and creativity of enterprise development. The government should encourage private enterprises to act as resources and introduce leading talents from the "Thousand Talents Program" and "Ten Thousand Talents Program" to work in private enterprises. Secondly, the government should encourage large-scale enterprises, universities, scientific research institutes, and public institutions to jointly build a batch of industrial technology collaborative innovation alliances and industrial collaborative innovation bases, so as to promote enterprises to truly become the main body of demand creation and talent cultivation. Enterprises should also establish and improve a relatively complete salary system, and attach importance to the influence of corporate culture, take innovation vitality as the theme, stimulate the creative thinking of employees, and cultivate employees' sense of innovation when training in the human resources department.

\subsection{Enhancing the Industrial Scale of High-tech Private Enterprises}

At present, Zhuhai City's high-tech industries are small in scale and slow in growth, resulting in insufficient capacity for agglomeration of innovative resources. The Zhuhai Municipal Government should guide and encourage government departments, enterprises and institutions to select and purchase the province's independent innovative products to provide market space for the growth of high-tech industries. It will be of great significance to strengthen the technological development and innovation of enterprises, support enterprises to apply for patent rights, organize more large-scale business exchange meetings, enhance their own reputation, and strive to build well-known brands. When enterprises are formulating $R \& D$ strategies, it is necessary for them to pay attention to the management of existing assets and regularly check corporate patents. For patents that still have application value, they should pay attention to daily maintenance and improve the efficiency of asset management. Opening innovation platforms of enterprises and universities can integrate the industrial chain, increase cooperative innovation between the upper, middle, and downstream of the industrial chain, integrate various innovation entities, and form a networked innovation structure. There are differences in the scale of private enterprises in Zhuhai. Enterprises want to interact with users or want to absorb the innovation capabilities of the public, but some enterprises have strong funds and large companies, and some enterprises have small funds or small 
corporate customers. Therefore, the municipal government should improve the communication between high-tech private enterprises, expand the scale of the industry, increase demand within China, and increase influence based on geographical advantages.

\section{CONCLUSION}

Under the innovation-driven strategy, the technological innovation of private enterprises in Zhuhai continues to develop. The overall private enterprises in Zhuhai are still small and numerous. There are still problems such as uneven government investment in scientific research, shortage of hightech talents, imperfect industrial chain, and weak driving effect of industrial upgrading. In the followup process of the innovation and development of private enterprises, the government should increase the investment in special scientific research according to the actual situation of private enterprises. Government and enterprises need to cooperate to continuously optimize and improve the talent introduction system, form an industrial chain in the multi-party linkage, and expand economies of scale. Innovation is the first driving force for development and the strategic support for the construction of a modern economic system. Zhuhai private enterprises continue to sum up experience and explore on the road of innovation and development, and eventually become modern highquality private enterprises in China.

\section{AUTHORS' CONTRIBUTIONS}

Xue Cheng wrote the manuscript, and Wei Chen contributed to revising and editing.

\section{REFERENCES}

[1] Zhang Li, Zhu Yanlin, The Improvement of Independent Innovation Ability of China's Small and Medium-sized Enterprises [J]. Northern Economy and Trade, 2019(08): 136137. (in Chinese)

[2] Wang Xiaofei, France Enacts the 2021-2030 Research Planning Law to Promote the Sustainable Development of Scientific Research [J]. China Scitechnology Business, 2020(10): 97-99. (in Chinese)

[3] Chen Junying, Qu Yanwei, Research on Science and Technology Innovation Financing of Private Enterprises [J]. Technology and
Economy of Changjiang, 2021, 5(S1): 164166. (in Chinese)

[4] Guo Sheng, Wei Wenfang, Research on Talent Strategy of Private Enterprises - Take Shiyan City as an Example [J]. Journal of Hubei Industrial Polytechnic, 2020, 33(04): 31-34. (in Chinese)

[5] Liu Guofeng, Li Rongxia, Song Jinjie, Research on the Innovation and Development Path of Baoding Private Enterprises [J]. Business \& Economy, 2020(10): 32-33. (in Chinese)

[6] Xu Zewei, Vigorously Stimulate the Creativity of Private Enterprises [N]. China Business Times, 2020-06-17(003). (in Chinese)

[7] Chen Yong, Research on Relationship Between Government Subsidies, Technological Innovation and Enterprise Performance of Private Enterprises [D]. South China University of Technology, 2020. (in Chinese) 